\title{
Carbohydrate Counting: Meals for Diabetes ${ }^{1}$
}

\author{
Cassie Rowe, Jamila R. Lepore, and Wendy J. Dahl²
}

Carbohydrates are a key nutrient of concern for adults with diabetes who take insulin. Counting carbohydrates is one method that can be used to help manage blood glucose (sugar) levels. While the number of carbohydrates is significant, it is equally important to consider the types of carbohydrate choices. A small apple may have the same number of grams of carbohydrate as two small cookies, but the apple contains more beneficial nutrients, including vitamins, minerals, water, and fiber. In fact, choosing high-fiber carbohydrate foods are best, as fiber helps resist quick blood glucose spikes so levels are better maintained. Both food choices and the number of carbohydrates are important in managing blood glucose levels. Proper nutrition can help to reduce the risk of complications from diabetes, such as heart disease and kidney disease. It is therefore important to learn to choose and enjoy the right types of carbohydrates in the appropriate quantities.

\section{Meal Planning: Small, Medium, and Large Carbohydrate Meals}

You have been given instructions for your insulin based on the carbohydrate "size" of your meal: small, medium, or large. It is important to include food containing carbohydrate at every meal, but it can be difficult to know what the sizes of small, medium, and large carbohydrate meals look like. In Tables 1-3, you'll find two examples for each type of meal, home-prepared meals versus restaurant meals, with the foods that contain carbohydrate underlined.
But first you need to learn which foods contain carbohydrate and an easy way to account for these foods in your meals. Why? While example meals are great to get started, you need to understand and be able to apply these concepts to any meal. You don't eat the same foods every day, so if you know how to count carbohydrates, eating appropriately sized and balanced meals will be easier than ever.

\section{Carbohydrate Counting}

What is carbohydrate counting?

"Carb" counting is a way to plan meals to help you maintain target blood glucose levels. Certain foods contain carbohydrate, and these are the foods that most influence your blood glucose. Your body needs carbohydrate in just the right amount. Not enough carbohydrate can lead to low blood glucose (hypoglycemia). Too much carbohydrate can lead to high blood glucose (hyperglycemia). This is why carb counting is a great tool to understand and practice because it can help you control your blood glucose and still give you the freedom to make varied food choices.

\section{What foods contain carbohydrate?}

Not all foods contain carbohydrate, and some foods contain a lot more than others.

So, which foods matter?

1. This document is FSHN12-18, one of a series of the Food Science and Human Nutrition Department, Florida Cooperative Extension Service, Institute of Food and Agricultural Sciences, University of Florida. Original publication date March 2013. Visit the EDIS website at http://edis.ifas.ufl.edu.

2. Cassie Rowe, MS, RD, graduate student; Jamila R. Lepore, MS, RD, graduate student; and Wendy J. Dahl, PhD, RD, assistant professor; Food Science and Human Nutrition Department, Institute of Food and Agricultural Sciences, University of Florida, Gainesville, FL 32611. 
Foods that contain carbohydrate

- Starchy vegetables (corn, potatoes, winter squash, sweet peas, legumes [peas and beans], and soy products like veggie burgers)

- Starchy grain products (bread, rice, pasta, and cereal)

- Fruit and fruit juices

- Milk and yogurt

- Sweets and snacks (cookies, cake, crackers, chips, candy, sugary beverages, and ice cream)

Foods that contain little or no carbohydrate

- Meat (beef, pork, lamb, veal, etc.), poultry, fish (without breading)

- Cheese

- Oil/butter

- Non-starchy vegetables (some carbohydrate, but very low)

- Nuts/seeds (some carbohydrate, but very low)

What serving size do I need?

According to the American Diabetes Association, an exchange of a carbohydrate food contains approximately 15 grams (g) of carbohydrate. Depending on your glycemic control, weight, and other health factors, your health care provider will suggest a certain amount of carbohydrate exchanges per meal to help keep your after-meal blood glucose levels within target ranges. Therefore, your health care provider may recommend a small, medium, or large carbohydrate meal depending on your needs. Thirty grams of carbohydrate are recommended for the small meal. This is equal to two $15 \mathrm{~g}$ servings of carbohydrate foods. For medium meals (60 g carbohydrate), there are four exchanges, and for large meals (90 g carbohydrate), there are six exchanges.

General serving sizes for common foods (each contains $\sim \mathbf{1 5}$ g carbohydrate per serving)

- 1 slice of bread

- 1/2 English muffin

- $1 / 4$ large bagel or muffin

- 1 (4-inch) pancake/waffle

- 1 (6-inch) tortilla

- $3 / 4$ cup unsweetened cereal

- $1 / 2$ cup cooked cereal (oatmeal, cream of wheat, grits)

- $1 / 3$ cup rice or pasta

- 6 small crackers
- $3 / 4$ ounce potato/tortilla chips

- 3 cups popcorn

- $1 / 2$ cup starchy vegetable (corn, peas, potato, beans)

- 8 ounces milk

- 6 ounces yogurt

- 1 small (4-ounce) fresh fruit

- $1 / 2$ cup canned fruit (drained) or fruit juice

- 3/4-1 cup fresh fruit

- 2 small (2-inch) cookies (sandwich crème filled, chocolate chip, peanut butter)

- $1 / 2$ cup ice cream/frozen yogurt

- 1 (1-ounce) granola bar

- 1/2 cup casserole (including lasagna, macaroni and cheese, or other casserole dishes)

- 1 tablespoon sugar, jam, jelly, or honey

- 2 tablespoons light maple syrup

The serving size varies depending on the particular food and brand, but keeping these common foods and servings in mind will help you estimate carbohydrate content when a food label isn't available. When eating out, request the nutrition information or check for it on the restaurant's website. Many restaurants have carbohydrate counts for their foods. If there is no nutrition information available or you don't have access to it, remember this page as a guide when making food choices. Don't see the food item on here? Choose the food that matches best.

Use the examples in the tables below as a guide for your meals. Read on, some of these meals might surprise you!

The meal examples listed in the tables can be altered to accommodate your likes and dislikes. Look at the home-prepared midday meal with $90 \mathrm{~g}$ of carbohydrate, for example. You may substitute an additional $1 / 3$ cup of pasta in place of the garlic toast and still only have $90 \mathrm{~g}$ of carbohydrate. Or look at the restaurant evening meal with $90 \mathrm{~g}$ of carbohydrate. You may substitute two slices of garlic bread in place of French fries and still have only $90 \mathrm{~g}$ of carbohydrate. As you can see, the carbohydrate size of a meal is not always what you would expect. To decide how other foods fit into small, medium, or large carbohydrate meals, just add the carbohydrate values in your meal together. Most restaurants have the nutrition facts for every menu item, both in the restaurant and online. Now that you have a better idea of what small, medium, and large carbohydrate meals look like, you'll be on your way to being in better control of your diabetes. Happy eating! 


\begin{tabular}{|c|c|}
\hline & \multirow{20}{*}{ 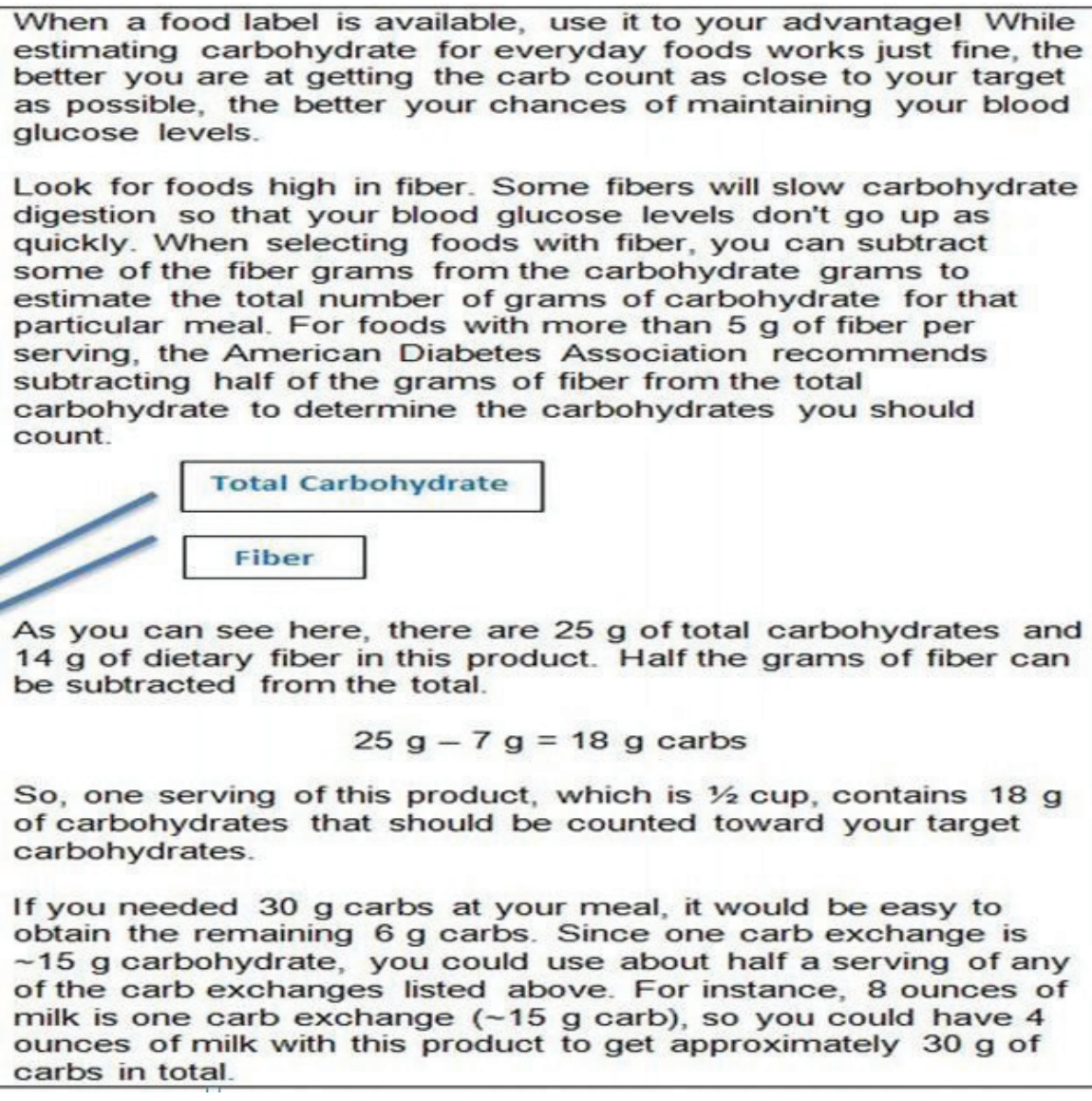 } \\
\hline & \\
\hline $\begin{array}{r}\text { Cereal with } \\
1 / 2 \text { cup } \\
\text { Cereal Skim Milk }\end{array}$ & \\
\hline Calories & \\
\hline Calories from Fat & \\
\hline \% Daily Value*: & \\
\hline Total Fat $1 \mathrm{~g}^{*}$ & \\
\hline Saturated Fat Og & \\
\hline Trans Fat Og & \\
\hline Polyunsaturated Fat $\mathbf{0 g}$ & \\
\hline Mon & \\
\hline Cholesterol Omg & \\
\hline Sodium $105 \mathrm{mg}$ & \\
\hline Potassium 130mg & \\
\hline Total Carbohydrate $25 \mathrm{~g} \quad 8 \%$ & \\
\hline Dietary Fiber $14 \mathrm{~g}$ & \\
\hline Soluble Fiber less than $1 \mathrm{~g}$ & \\
\hline Sugars Og & \\
\hline Othe & \\
\hline Protein $2 \mathrm{~g}$ & \\
\hline
\end{tabular}

Figure 1. How to use a food label with carb counting

\section{NOTES}


Table 1. Small carbohydrate meal examples

\begin{tabular}{|c|c|c|}
\hline Meal example & Home-prepared meal & Restaurant meal \\
\hline Morning meal & $\begin{array}{l}1 \text { scrambled egg w/2 oz cheese AND } 1 \text { slice of } \\
\text { toast with butter }(15 \mathrm{~g}) \text { AND } 11 / 4 \text { cup whole } \\
\underline{\text { strawberries }(15 \mathrm{~g})}\end{array}$ & 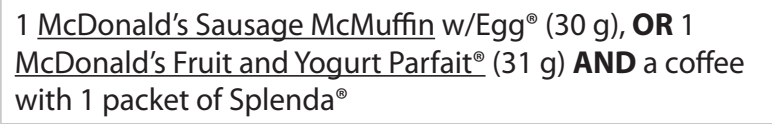 \\
\hline Midday meal & $\begin{array}{l}1 \text { lunchmeat sandwich with } 2 \text { slices of reduced } \\
\text { carb bread, } 1 \text { slice tomato, } 2 \text { oz cheese, and } \\
\text { condiments (mayo/mustard) ( } 15 \mathrm{~g} \text { ) AND } 1 / 2 \text { cup } \\
\text { no-sugar-added pudding made with fat-free milk } \\
\text { (15 g) AND } 1 \text { can diet soda }\end{array}$ & $\begin{array}{l}\text { Subway }{ }^{\circledast} \text { Club Salad }(11 \mathrm{~g}) \text { AND } 1 \text { package ranch dressing } \\
(3 \mathrm{~g}) \text { AND } 1 \text { container Dannon Light \& Fit }{ }^{\circledast} \text { yogurt }(16 \mathrm{~g}) \\
\text { AND unsweetened tea }\end{array}$ \\
\hline Evening meal & $\begin{array}{l}6 \text { oz broiled salmon AND } 1 / 3 \text { cup (cooked) brown } \\
\underline{\text { rice }(15 \mathrm{~g}) \text { AND } 3 / 4 \text { cup bell peppers }+1 / 4 \text { cup corn }} \\
(15 \mathrm{~g}) \text { AND } 1 \text { can diet soda }\end{array}$ & $\frac{\text { Sonny's }{ }^{\circledast} \text { Barbecue Caesar salad }(30 \mathrm{~g}) \text { with chargrilled }}{\text { chicken AND } 1 \text { can diet soda }}$ \\
\hline
\end{tabular}

Table 2. Medium carbohydrate meal examples

\begin{tabular}{|c|c|c|}
\hline Meal example & Home-prepared meal & Restaurant meal \\
\hline Morning meal & $\begin{array}{l}1 \frac{1}{2} \text { cups Plain } \text { Cheerios }^{\circledast}(30 \mathrm{~g}) \text { AND } 1 \text { cup } 1 \% \text { milk } \\
\text { (15 g) AND } 1 / 2 \text { small banana }(15 \mathrm{~g}) \text { AND coffee with } 1 \\
\text { packet Splenda }{ }^{\circledast}\end{array}$ & $\begin{array}{l}1 \text { McDonald's Sausage McMuffin with Egg }{ }^{\circledast}(30 \mathrm{~g}) \text {, OR } 1 \\
\text { McDonald's Fruit and Yogurt Parfait }{ }^{\circledast}(31 \mathrm{~g}) \text { AND } 2 \underline{\text { hash }} \\
\underline{\text { browns }^{2}(30 \mathrm{~g}) \text { AND a coffee with } 1 \text { packet of Splenda }}\end{array}$ \\
\hline Midday meal & $\begin{array}{l}1 \text { lunchmeat sandwich on } 2 \text { slices bread with } 1 \text { slice } \\
\text { tomato, } 2 \text { oz cheese, and condiments (mayo/mustard) } \\
(30 \mathrm{~g}) \text { AND } 11 \frac{1}{2} \text { oz ( } 30-40 \text { chips) Baked Lay's }{ }^{\otimes} \text { potato } \\
\text { chips ( } 30 \mathrm{~g}) \text { AND } 1 \text { can diet soda }\end{array}$ & $\begin{array}{l}\text { Subway }{ }^{\circledast} 6^{\prime \prime} \text { turkey sub with bread, cheese, lettuce, } \\
\text { tomato, green peppers, onion, cucumber, and condiments } \\
\text { (mayo/mustard) }(45 \mathrm{~g}) \text { AND } 1 \text { container Dannon Light \& } \\
\left.\text { Fit }^{\oplus} \text { yogurt ( } 16 \mathrm{~g}\right) \text { AND unsweetened tea }\end{array}$ \\
\hline Evening meal & $\begin{array}{l}6 \mathrm{oz} \text { grilled chicken AND } 1 \text { cup mashed potatoes } \\
\text { with } 2 \text { oz cheese and butter ( } 30 \mathrm{~g}) \text { AND } 1 / 2 \text { cup peas } \\
(15 \mathrm{~g}) \text { AND } 1 \text { cup fresh fruit }(15 \mathrm{~g}) \text { AND unsweetened } \\
\text { tea }\end{array}$ & $\begin{array}{l}\text { Sonny's }{ }^{\circledast} \text { Barbecue lunch portion of pulled beef brisket } \\
\text { (no bun) ( } 12 \mathrm{~g} \text { ) AND } 1 / 2 \text { large sweet potato ( } 30 \mathrm{~g}) \text { AND } \\
\text { 2-inch piece of cornbread (15g) AND } 1 / 2 \text { cup cooked non- } \\
\text { starchy vegetables ( } 5 \mathrm{~g} \text { ) AND } 1 \text { can diet soda }\end{array}$ \\
\hline
\end{tabular}

Note: A medium carbohydrate meal is based on about $60 \mathrm{~g}$ of carbohydrate. Foods that contain carbohydrate are underlined.

Table 3. Large carbohydrate meal examples

\begin{tabular}{|c|c|c|}
\hline Meal example & Home-prepared meal & Restaurant meal \\
\hline Morning meal & $\begin{array}{l}1 \text { Thomas }^{\oplus} \text { Everything bagel }(50 \mathrm{~g}) \text { AND } 2 \\
\text { oz cream cheese AND } 1 / 2 \text { small banana ( } 30 \\
\text { g) AND } 1 \text { cup } 1 \% \text { milk }(15 \mathrm{~g})\end{array}$ & $\begin{array}{l}2 \text { McDonald's Sausage McMuffin with } \text { Egg }^{\oplus}(60 \mathrm{~g}), \text { OR } 1 \\
\text { Hotcakes and Sausage }(60 \mathrm{~g}) \text { AND } 2 \text { hash browns }(30 \mathrm{~g}) \text { AND } \\
\text { coffee with } 1 \text { packet of Splenda }{ }^{\circledR}\end{array}$ \\
\hline Midday meal & $\begin{array}{l}2 / 3 \text { cup cooked pasta }(30 \mathrm{~g}) \text { AND } 1 / 2 \text { cup } \\
\text { Ragu }{ }^{\circledR} \text { pasta sauce }(15 \mathrm{~g}) \text { AND } 1 \text { slice toast } \\
(15 \mathrm{~g}) \text { with cheese and garlic AND } 1 \text { cup } \\
\text { cooked spinach }+1 / 2 \text { cup tomatoes }(15 \mathrm{~g}) \\
\text { AND } 1 \text { small apple }(15 \mathrm{~g}) \text { AND } 1 \text { can diet } \\
\text { soda }\end{array}$ & $\begin{array}{l}\text { Subway }{ }^{\circledast} 6 \text { " turkey sub with bread, cheese, lettuce, tomato, } \\
\text { green peppers, onion, cucumber, and condiments (mayo/ } \\
\text { mustard) ( } 45 \mathrm{~g} \text { ) AND } 1 \text { container Dannon Light \& Fit }{ }^{\circledast} \\
\text { yogurt ( } 16 \mathrm{~g}) \text { AND } 1 \text { chocolate chunk cookie ( } 30 \mathrm{~g}) \text { AND } \\
\text { unsweetened tea }\end{array}$ \\
\hline Evening meal & $\begin{array}{l}2 \text { slices of supreme Digiorno }{ }^{\oplus} \text { Rising Crust } \\
\text { pizza ( } 1 / 3 \text { of pizza) }(82 \mathrm{~g}) \text { AND salad with } 1 \\
\text { cup spinach, } 1 / 4 \text { cup carrots, } 1 / 4 \text { cup tomato, } \\
\frac{1 / 2 \text { cup cucumber }(10 \mathrm{~g}) \text { AND } 2 \text { tbsp. Italian }}{\text { dressing AND unsweetened tea }}\end{array}$ & $\begin{array}{l}\text { Sonny's }{ }^{\circledast} \text { Barbecue lunch portion of pulled beef brisket } \\
\text { (no bun) (12 g) AND } 3 / 4 \text { large sweet potato (45g) AND } \\
\text { 2-inch piece of cornbread (15g) AND } 1 \frac{112 \text { cups non-starchy }}{\text { vegetables (15g) AND } 1 \text { can diet soda }}\end{array}$ \\
\hline
\end{tabular}

Note: A large carbohydrate meal is based on about $90 \mathrm{~g}$ of carbohydrate. Foods that contain carbohydrate are underlined. 